\title{
Intravesical and transperitoneal laparoscopy in the management of tumor in the residual ureter
}

Anibal Wood Branco, Luciano Stunitz, Sandro Nichele, Paulo Henrique Douat, Murilo Luiz, Lucas Tha Nassif

Department of Urology Cruz Vermelha Hospital and Vita Batel Hospital, Curitiba, Brazil

The ocurrence of tumor in the residual ureter after an incomplete nephroureterectomy required by a tumor of renal collecting system is an uncommon but a well described situation. The recommended treatment in this situation is the radical excision of the remaining ureter, being the open technique the most used approach. The aim of this video is to demonstrate a new approach using intravesical and transperitoneal laparoscopy to remove the residual ureter following the oncological concepts. A 67 year-old male patient underwent an incomplete open right radical nephroureterectomy for a transitional cell carcinoma of the renal collecting system. After 16 months, the cystoscopy diagnostic revelead a recurrence of it in the residual ureter. An intravesical approach followed by a transperitoneal laparoscopy has removed the remaining ureter. Operative time was 110 minutes, blood loss $100 \mathrm{~mL}$, the patient was discharged on the first postoperative day and the Folley cateter was removed on the seventh one. Pathological examination revelead low grade transitional cell carcinoma and free surgical margins, no recurrence was observed after six months. To our knowledge, this is the first treatment description of a tumor in the residual ureter with these techniques. This approach can be a minimal invasive alternative in this unusual situation.

\section{ARTICLE INFO}

Available at: www.brazjurol.com.br/videos/march_april_2013/Branco_291_292video.htm

Int Braz J Urol. 2013; 39 (Video \#4): 291-2

Submitted for publication:

January 30,2013

Correspondence address: Dr. Anibal Wood Branco

Accepted after revision:

March 01, 2013 


\section{EDITORIAL COMMENT}

Dr. Branco et al. present a very nice case demonstrating and describing the laparoscopic excision of a retained distal ureter containing tumor 16 months following a right subtotal nephroureterectomy for upper tract urothelial carcinoma. This should be a very uncommon scenario as the standard of care is a complete nephroureterectomy to include the kidney, the entire ureter and a cuff of bladder. A significant percentage of patients experience disease recurrence in the ipsilateral distal ureter if it is allowed to remain in-situ. This case demonstrates a tumor recurrence that under most circumstances should be preventable. However, the authors provide us with a nice depiction of a minimally invasive surgical approach to manage this uncommon scenario.

Dr. Wade J. Sexton Associate Member Urologic Oncology Fellowship Director Genitourinary Oncology Program Moffitt Cancer Center Tampa, Florida E-mail:wade.sexton@moffitt.org 